\title{
Sulforaphane and Epigallocatechin Gallate Restore Estrogen Receptor Expression by Modulating Epigenetic Events in the Breast Cancer Cell Line MDA-MB-231: A Systematic Review and Meta-Analysis
}

\author{
Vincenza Gianfredi ${ }^{a}$ Samuele Vannini ${ }^{b}$ Massimo Moretti ${ }^{b} \quad$ Milena Villarini $^{b}$ \\ Nicola Luigi Bragazzic Alberto Izzottic Daniele Nuccid \\ a School of Specialization in Hygiene and Preventive Medicine, Department of Experimental \\ Medicine, and ${ }^{b}$ Department of Pharmaceutical Sciences, Unit of Public Health, University of Perugia, \\ Perugia, ' Department of Health Sciences (DISSAL), Unit of Public Health, University of Genoa, \\ Genoa, and d Digestive Endoscopy Unit, Veneto Institute of Oncology IOV-IRCCS, Padua, Italy
}

\section{Keywords}

Epigenetics $\cdot$ Sulforaphane $\cdot$ Epigallocatechin gallate $\cdot$ Apoptosis $\cdot$ Breast cancer

\begin{abstract}
Background/Aims: Epigenetics refers to modifications in gene activity and expression without alteration at the DNA sequence. Environment and diet could influence gene expression. Diet modifications may be meaningful in preventing and treating chronic diseases, cancer included. Dietary bioactive compounds, such as polyphenols (e.g., curcumin, resveratrol, or epigallocatechin gallate [EGCG]) or isothiocyanate (e.g., sulforaphane [SFN]), can regulate histone acetylation. The aim of this systematic review and meta-analysis was to evaluate the effect of SFN and EGCG on breast cancer (BC) cells cultured in vitro. Methods: Due to the enormous variability observed in study protocols and the innumerable genes involved, only studies analyzing the number of apoptotic cells in the MDA-MB-231 cell line were evaluated. The effect size (ES) was computed as the ratio of means. Results: We identified 7 studies, 4 regarding the effect of $10 \mu \mathrm{M}$ SFN on MDA-MB-231 cells ( $E S=4.59,95 \%$ confidence interval $4.05-5.20$ ) and 3 focusing on the impact of $20 \mu \mathrm{M}$ EGCG (ES = 2.84, 95\% confidence interval 2.60-3.10). Conclusion: The findings suggest beneficial effects of dietary bioactive compounds such as SFN and EGCG and their effect on $\mathrm{BC}$ cells by restoring estrogen receptor gene expression, modulating epigenetic changes and events, and interfering with tumor growth rate. Publication bias limits the generalizability of the conclusions. High-quality studies are needed.

V. Gianfredi and S. Vannini contributed equally to this work. 


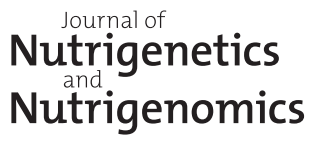

\section{Introduction}

Epigenetic mechanisms, such as chromatin remodeling, histone modifications, nucleosome repositioning, and direct/indirect modulation of gene expression by noncoding RNAs such as microRNAs [1], are of crucial importance in ensuring proper development and stability of tissue-specific gene expression patterns in mammals [2]. Epigenetic dysregulations can result in malignant cell transformation, providing a link between cellular adaptation to tumor microenvironment and plasticity [3].

Understanding epigenetic changes plays a central role not only in cancer etiopathogenesis, but also in cancer prevention and therapy. Modifications of specific sites of histones which are involved in the organization of the chromatin structure and in the regulation of gene transcription can induce changes in the transcription of various genes [4]. Inhibitors of histone deacetylases have been shown to reactivate the silenced tumor suppressor gene $[5,6]$.

Besides the biological makeup with its genetic/epigenetic dysregulations, lifestyles, such as nutrition, play a major role both in the etiopathogenesis and prevention of cancer, also influencing epigenetic events. According to the American Institute for Cancer Research (AICR) and the World Cancer Research Fund (WCRF), one-third of tumors may be attributable to nutrition [7], which means that a significant amount of tumor cases could be prevented through the adoption of a healthy diet [8]. Bioactive dietary compounds can potentially reactivate silenced genes or suppress oncogenes, restoring aberrant methylation patterns. Therefore, a new, exciting specialty termed "nutri-epigenetics," deriving from the intersection of nutritional science and epigenetics, is emerging $[9,10]$.

Despite important achievements and improvements in clinical outcomes, cancer still imposes a heavy epidemiological and societal burden [11]. The conventional treatment shows side effects on healthy cells and, therefore, identifying alternative methodologies is crucial. For example, with few or negligible adverse effects, dietary bioactive compounds show chemopreventive effects, especially at low doses and at physiological concentrations, repressing phase 1 detoxification enzymes and inducing phase 2 enzymes, favoring cell cycle arrest, inducing apoptosis, and inhibiting cellular proliferation [9, 10, 12]. In 2004, Hu et al. [13] proved, in a murine model, that oral administration of $50 \mu \mathrm{M}$ sulforaphane (SFN), an isothiocyanate derived from glucosinolates, induces a 20- $\mu \mathrm{M}$ plasmatic peak of the compound which, due to allosteric inhibition of histone deacetylase, epigenetically determines an increase in histone acetylation at the level of gene promoters and, as such, the activation of a number of tumor suppressor genes, including p21. Song et al. [14], utilizing a bioinformatic approach, predicted the networks and pathways affected by the administration of epigallocatechin gallate (EGCG) in tumor cells. EGCG is one of the most commonly found and active catechins, usually present in green tea. Its administration could impact on different biological processes and events such as cell cycle, cellular assembly and organization, DNA replication, recombination and repair, and cell death and survival, among others.

The aim of this systematic review and meta-analysis was to evaluate the role of two dietary bioactive compounds, SFN and EGCG, focusing on breast cancer (BC), given its epidemiological and clinical relevance. Both incidence and related mortality have increased by $18 \%$ since 2008 , and the annual global burden of BC is expected to reach 3.2 million new cases by 2050 [15]. As such, the effect of SFN and EGCG in restoring estrogen receptor (ER) expression modulating epigenetic events on $\mathrm{BC}$ cells cultured in vitro was assessed. 


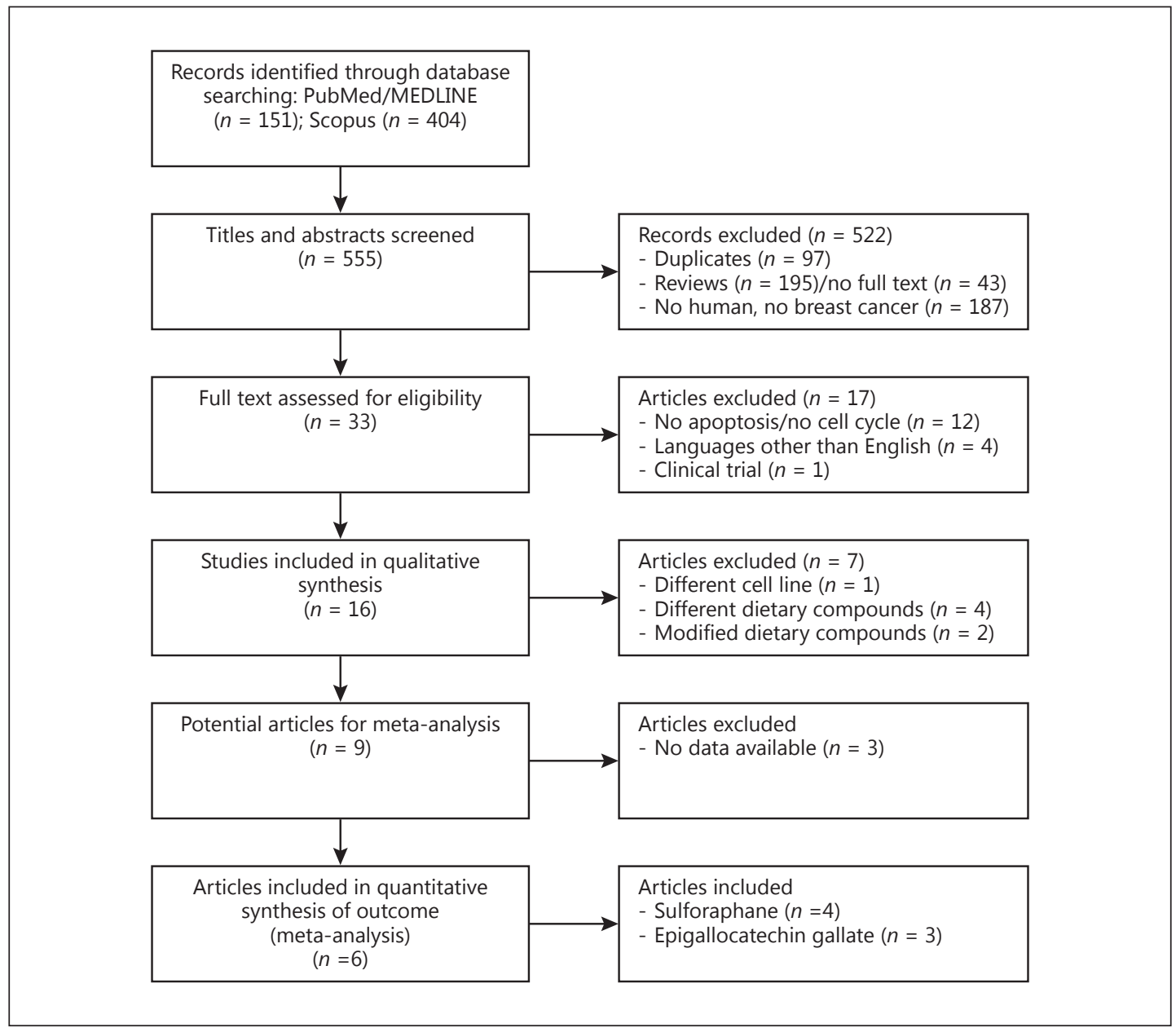

Fig. 1. Flowchart showing the study selection process.

\section{Materials and Methods}

\section{Data Sources and Searches}

This systematic review and meta-analysis was conducted in accordance with the Preferred Reporting Items for Systematic Reviews and Meta-Analyses (PRISMA) guidelines [16].

On February 2, 2016, two researchers (V.G. and D.N.) independently searched from inception two major scholarly databases, PubMed/MEDLINE and Scopus, using ad hoc, pre-established search terms related to dietary bioactive compounds, BC, and epigenetics. Where appropriate, medical subject headings (MeSH) terms and wildcard options were used. More in details, the used string was: (dietary compound OR sulforaphane OR SFN OR epigallocatechin OR EGCG) AND (epigen* OR nutrigen* OR DNA methylation OR histone modification) AND (cancer prevention OR breast cancer OR cancer). The search was limited to articles published in English, and only full-text papers were taken into consideration for inclusion. To identify further potentially eligible studies, a manual check of the reference lists of each included study was carried out.

\section{Study Selection}

The study selection process is summarized in Figure 1. Due to the enormous variability observed in study protocols and the different roles played by the innumerable genes involved in cell cycle arrest and in the regulation of apoptosis, only studies analyzing the number of apoptotic cells in the MDA-MB-231 BC cell line were evaluated. The doses considered for inclusion of studies in this meta-analysis were selected on the 
Gianfredi et al.: SFN and EGCG Restore ER Expression by Modulating Epigenetic Events in the BC Cell Line MDA-MB-231: A Systematic Review and Meta-Analysis

basis of physiological bioavailability evaluated after a common assumption based on $68 \mathrm{~g}$ of broccoli sprouts (approximately $105 \mathrm{mg} \mathrm{SFN}$ ) and 3-4 cups of green tea (approximately $200 \mathrm{mg}$ EGCG) [5, 17-19].

The MDA-MB-231 cell line are a mammary BC cell line derived from metastatic site with pleural effusion. The cell line is aneuploid female (modal number $=64$, range $=52-68$ ), with chromosome counts in the neartriploid range; normal chromosomes N8 and N15 are absent [20].

Initially, two researchers (V.G. and D.N.) independently screened the titles and abstracts of all papers in order to exclude studies that clearly did not meet the inclusion criteria. The full-text versions of all potentially relevant studies were screened independently by three researchers (V.G., D.N., and S.V.). Data extraction and quality assessment were carried on autonomously by three researchers (V.G., D.N., and N.L.B.). Disagreements were resolved through discussions until consensus was reached. If discrepancies still existed, the opinions of three other researchers (M.M., M.V., and A.I.) were sought for further discussion.

Articles were considered eligible if they met the following inclusion criteria: (1) evaluation of the biological effects of SFN or EGCG dietary bioactive compounds on human BC cells cultured in vitro; (2) epigenetic DNA modification induced by the considered bioactive compounds; (3) apoptosis induced by SFN or EGCG tested in vitro at least in triplicate; and (4) human BC cell line MDA-MB-231. Only papers providing a clear description of the study design and findings were considered in depth.

Exclusion criteria were: (1) full-length articles not written in English; (2) tests conducted in vivo; (3) abstracts, case reports, letters to the editor, editorials, commentaries, reviews without original data, studies with lack of control groups, or appropriate data for extraction; and (4) tests performed in cell lines different from MDA-MB-231.

\section{Data Extraction}

The data, extracted independently by two authors (V.G. and D.N.), were recorded on a standard spreadsheet. Extracted data included the main characteristic of each study (authors, year, country of publication, and study design), characteristics of the cells (cell line, gene expression), characteristics of treatment (bioactive dietary compound, dosage, duration), and the reported results (when numerical values of results were lacking, data were extrapolated from graphs). The secondary outcomes represented the effect(s) on cell cycle and/or the modification of gene expression.

Data Synthesis and Analysis

The traditional pairwise meta-analysis method was used to directly analyze the dietary bioactive compound-induced apoptosis. A fixed-effects model was applied. The effect size (ES) in the present metaanalysis was computed as the ratio of means (RoM) with its $95 \%$ confidence intervals (CIs) [21, 22]. The RoM is defined as the mean value in the exposed group (cells treated with dietary bioactive compound) divided by the mean value in the control group (untreated cells). The statistical heterogeneity among studies was assessed by the $\chi^{2}$ test and $I^{2}$ statistics. A $p$ value $<0.05$ was considered statistically significant.

The meta-analysis was carried out using the open-source Review Manager (RevMan 5.3) software (The Cochrane Collaboration, The Nordic Cochrane Centre, Copenhagen). Publication bias was also assessed when appropriate by visually inspecting funnel plots [23].

\section{Results}

\section{Study Characteristics and Quality}

The initial search strategy yielded 555 records (151 from PubMed/MEDLINE and 404 from Scopus). Out of the 555 items, 97 were duplicates and were therefore excluded. After the initial screening of titles and abstracts, a further 238 items (195 reviews and metaanalyses and 43 non-full-text papers: conference papers, articles unrelated to the topic of the current systematic review) were excluded. Furthermore, another 187 articles were excluded (no human cells and/or no BC cells). Thirty-three full-text articles were retrieved and assessed. Out of these 33 articles, 24 studies were excluded for the following reason: (i) articles not written in English (4 studies, 3 in Chinese and 1 in German); (ii) articles not focusing on cell cycle and/or apoptosis (12 studies); (iii) articles investigating chemically modified dietary compounds ( 2 studies); (iv) quantitative data insufficient or not available (3 studies); (v) cell 
Gianfredi et al.: SFN and EGCG Restore ER Expression by Modulating Epigenetic Events in the BC Cell Line MDA-MB-231: A Systematic Review and Meta-Analysis

Table 1. Main characteristics of the four studies included in the meta-analysis related to the role of SFN and apoptosis induction in MDA-MB-231 breast cancer cells

\begin{tabular}{|c|c|c|c|c|c|c|}
\hline $\begin{array}{l}\text { Reference (first author), } \\
\text { journal, country }\end{array}$ & $\begin{array}{l}\text { SFN, } \\
\mu \mathrm{M}\end{array}$ & Treated & Control & OR $(95 \% \mathrm{CI})$ & Cell line & $\begin{array}{l}\text { Treatment } \\
\text { duration }\end{array}$ \\
\hline Meeran, 2010 [25], PLoS One, USA & 10 & 3 & 3 & $5.91(5.07-6.89)$ & MDA-MB-231 & 6 days \\
\hline Meeran, 2012 [29], PLoS One, USA & 10 & 3 & 3 & $6.90(4.36-10.92)$ & MDA-MB-231 siRNA & $72 \mathrm{~h}$ \\
\hline Meeran, 2012 [29], PLoS One, USA & 10 & 3 & 3 & $7.91(5.39-11.60)$ & MDA-MB-231 ER siRNA & $72 \mathrm{~h}$ \\
\hline Deb, 2014 [26], Tumour Biol, India & 10 & 3 & 3 & $19.80(4.32-90.80)$ & MDA-MB-231 & $24 \mathrm{~h}$ \\
\hline $\begin{array}{l}\text { Lubecka-Pietruszewska, } 2015 \text { [24], } \\
\text { J Nutrigenet Nutrigenomics, Poland }\end{array}$ & 10 & 3 & 3 & $0.87(0.64-1.19)$ & MDA-MB-231 & $96 \mathrm{~h}$ \\
\hline
\end{tabular}

line other than MDA-MB-231 (1 study); (vi) clinical trial (1 study); (vii) studies assessing folic acid (1 study) or curcumin (3 studies) as dietary compounds.

Finally, 6 papers were retained for the current meta-analysis. Since one of them analyzed two different MDA-MB-231 cell lines (ER+ and ER-), we considered it as two separate studies. In conclusion, 4 studies focused on SFN and 3 on EGCG.

\section{SFN-Induced Apoptosis in MDA-MB-231 Cells}

The data extracted from the studies are shown in Table 1. All studies were carried out within the last 6 years. Two studies were conducted in the USA, 1 in Poland, and 1 in India. Referring to apoptosis, the authors indicated an increase in apoptosis rate in 4 cases, while in 1 study this effect could not be observed. Two studies analyzed the standard MDA-MB-231 cell line [24, 25], while one study [26] analyzed MDA-MB-231 cells both with and without ER $\alpha$ expression. The concentration of SFN, tested in the included studies, was $10 \mu \mathrm{M}$.

The studies showed a high statistical heterogeneity ( $p$ for $\chi^{2}<0.0001, I^{2}=97 \%$ ). The forest plot in Figure 2a shows a RoM of 4.59 (95\% CI 4.05-5.20). The asymmetrical funnel plot (Fig. 2b) shows some potential publication bias.

\section{EGCG-Inducted Apoptosis in MDA-MB-231 Cells}

The included studies are reported in Table 2. They were conducted between 2007 and 2012 [27-29]. Two studies were conducted in USA and one in the UK. In all cases the authors indicated an increase in apoptosis rate. The concentration of EGCG, which was tested in two of the included studies [27, 29] was $20 \mu \mathrm{M}$, whereas Moiseeva et al. [28] used $8 \mu \mathrm{M}$ EGCG. The studies showed a high statistical heterogeneity ( $p$ for $\chi^{2}<0.0001, I^{2}=98 \%$ ). The forest plot in Figure 3a shows a RoM of 2.84 (95\% CI 2.60-3.10) for MDA-MB-231 cells treated with $20 \mu \mathrm{M}$ EGCG. The asymmetrical funnel plot (Fig. 3b) shows some potential publication bias.

\section{Epigenetic Changes}

The epigenetic changes induced by SFN and EGCG are shown for each study in Table 3. The genes studied were phosphatase and tensin homologue (PTEN), retinoic acid receptor beta 2 (RAR $\beta 2$ ), human telomerase reverse transcriptase (hTERT), ER $\alpha$, caveolin 1 (CAV1), and interleukin 6 (IL6). After treatment, all genes but hTERT resulted upregulated. Different molecular mechanisms were involved: changes in histone marks, modulation of the transcription factors, and condensation of the chromatin structure, among others. 


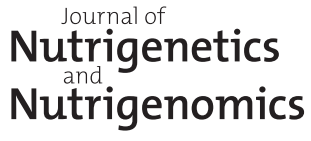

\begin{tabular}{l|l}
\hline J Nutrigenet Nutrigenomics 2017;10:126-135 \\
\hline DOI: 10.1159/000480636 & $\begin{array}{l}\text { @ 2017 S. Karger AG, Basel } \\
\text { www.karger.com/jnn }\end{array}$ \\
\hline
\end{tabular}

Gianfredi et al.: SFN and EGCG Restore ER Expression by Modulating Epigenetic Events in the BC Cell Line MDA-MB-231: A Systematic Review and Meta-Analysis

Table 2. Main characteristics of the three studies included in the meta-analysis related to the role of EGCG and apoptosis induction in MDA-MB-231 breast cancer cells

\begin{tabular}{|c|c|c|c|c|c|c|}
\hline $\begin{array}{l}\text { Reference (first author), } \\
\text { journal, country }\end{array}$ & $\begin{array}{l}\text { EGCG, } \\
\mu \mathrm{M}\end{array}$ & Treated & Control & OR $(95 \% \mathrm{CI})$ & Cell line & $\begin{array}{l}\text { Treatment } \\
\text { duration }\end{array}$ \\
\hline $\begin{array}{l}\text { Moiseeva, } 2007 \text { [28], } \\
\text { Mol Cancer Ther, UK }\end{array}$ & 8 & 16 & 16 & $2.00(1.80-2.22)$ & MDA-MB-231 & $30 \mathrm{~h}$ \\
\hline $\begin{array}{l}\text { Meeran, } 2011 \text { [27], Cancer } \\
\text { Prev Res (Phila), USA }\end{array}$ & 20 & 3 & 3 & $6.50(4.89-8.62)$ & MDA-MB-231 & 9 days \\
\hline $\begin{array}{l}\text { Meeran, } 2011 \text { [27], Cancer } \\
\text { Prev Res (Phila), USA }\end{array}$ & 20 & 3 & 3 & $8.62(6.42-11.57)$ & MDA-MB-231 & 12 days \\
\hline $\begin{array}{l}\text { Meeran, } 2012 \text { [29], PLoS } \\
\text { One, USA }\end{array}$ & 20 & 3 & 3 & $6.00(3.78-9.52)$ & MDA-MB-231 siRNA & $72 \mathrm{~h}$ \\
\hline $\begin{array}{l}\text { Meeran, } 2012 \text { [29], PLoS } \\
\text { One, USA }\end{array}$ & 20 & 3 & 3 & $7.13(4.81-10.57)$ & MDA-MB-231 ER siRNA & $72 \mathrm{~h}$ \\
\hline
\end{tabular}

CI, confidence interval; EGCG, epigallocatechin gallate; ER, estrogen receptor; OR, odds ratio; siRNA, small interfering RNA.

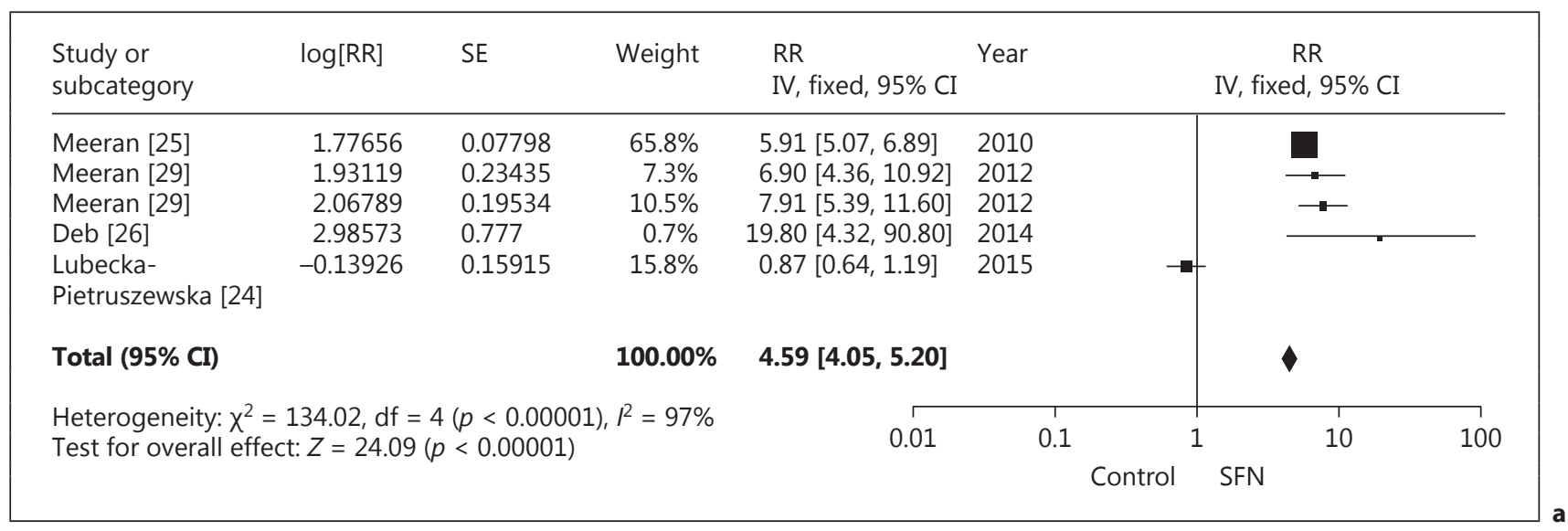

Fig. 2. Forest plot (a) and funnel plot (b) of the meta-analysis comparing the SFNtreated MDA-MB-231 cell line versus the untreated (control) MDA-MB-231 cell line in the induction of apoptosis (4 studies). CI, confidence interval; RR, rate ratio; SFN, sulforaphane.

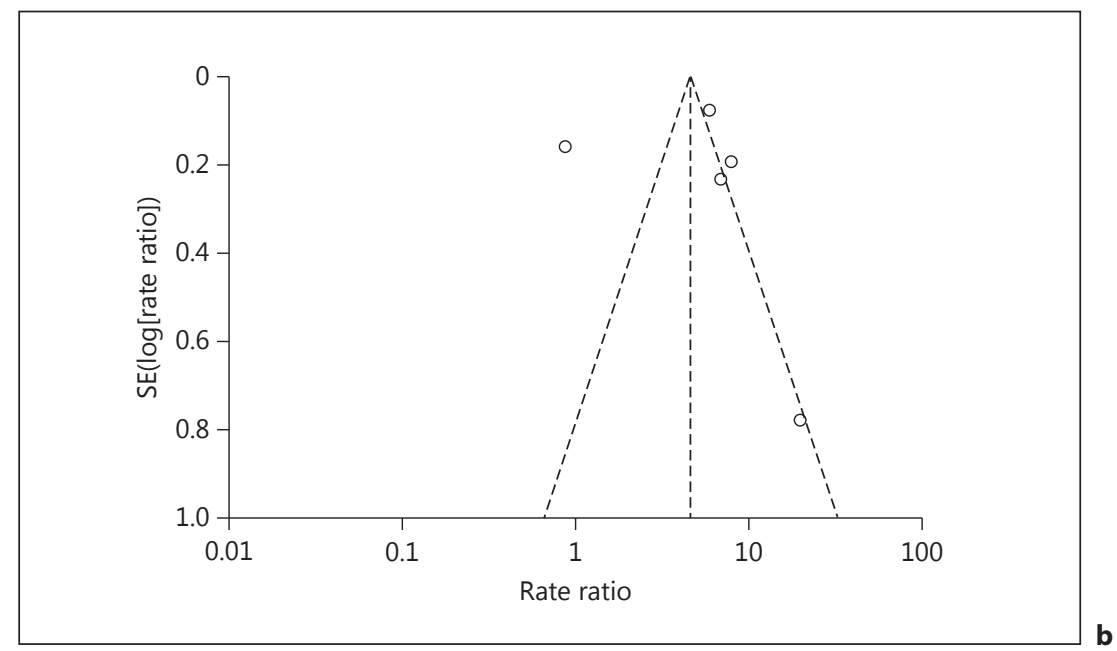


Gianfredi et al.: SFN and EGCG Restore ER Expression by Modulating Epigenetic Events in the BC Cell Line MDA-MB-231: A Systematic Review and Meta-Analysis

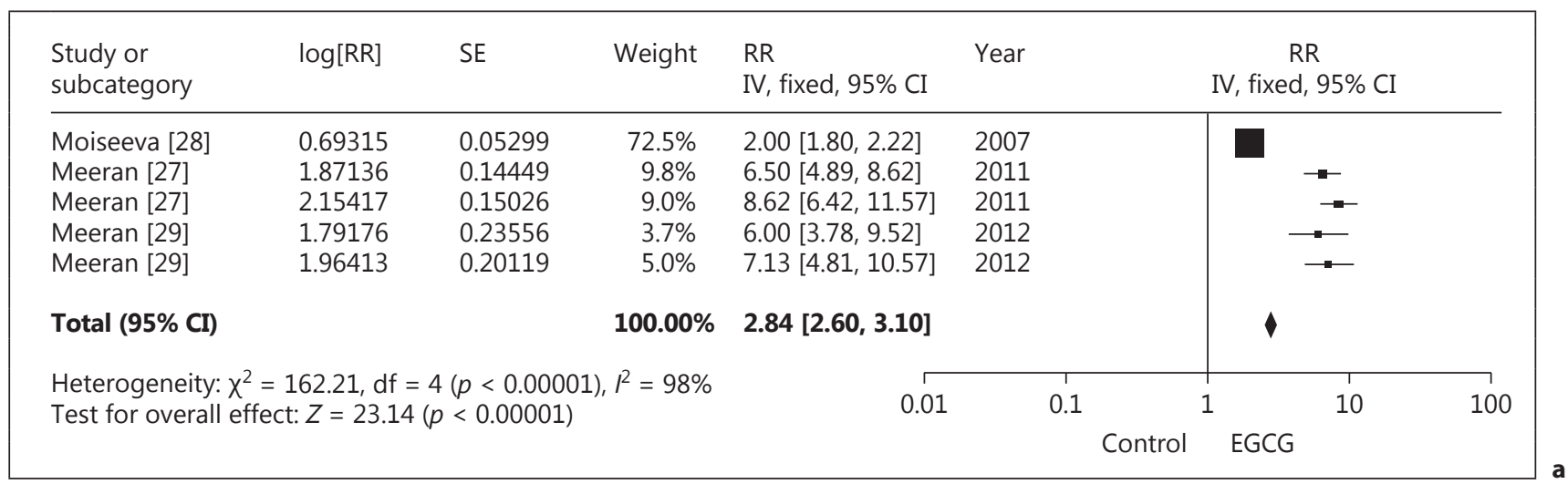

Fig. 3. Forest plot (a) and funnel plot (b) of the meta-analysis comparing the EGCGtreated MDA-MB-231 cell line versus the untreated (control) MDA-MB-231 cell line in the induction of apoptosis (3 studies). CI, confidence interval; EGCG, epigallocatechin gallate; $\mathrm{RR}$, rate ratio.

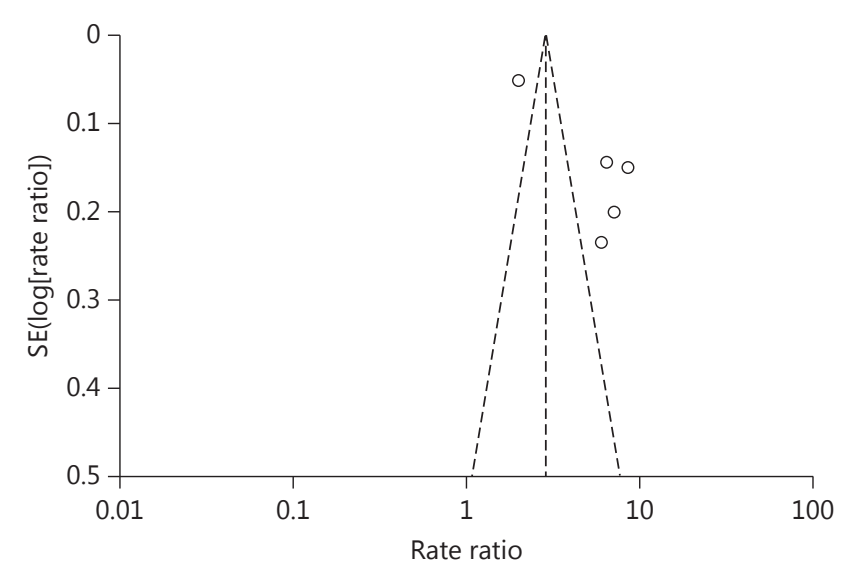

Epigenetic Changes Induced by SFN

SFN has an impact on PTEN and RAR $\beta 2$ expression, which finely modulate the methylation machinery and its core components (p21, p53, DNA methyltransferase 1 [DNMT1]), acting in a dose-dependent and in a dose-independent way, respectively. Moreover, methylation at the level of PTEN and RAR $\beta 2$ promoters can confer an invasive potential to all cells. Even though PTEN and RAR $\beta 2$ encode proteins potentially able to indirectly reduce the level of DNMT1 by downregulating the intracellular oncogenic mitogen-activated protein kinase/ activator protein 1 signaling cascade, this hypothesized effect could not be detected in the MDA-MB-231 cell line. No DNMT1 suppression was noticed, while p21 was found to be upregulated through the p53-independent pathway [24].

Furthermore, SFN leads to reactivation of ER $\alpha$, whose expression was found to be consistently correlated with ER $\alpha$ promoter hypomethylation and hyperacetylation [29]. Moreover, SFN repressed hTERT expression in a dose- and time-dependent way, with demethylation occurring mainly at the level of the first exon, facilitating the binding of the repressor CTCF and leading to a decrease in DNMT1 and DNMT3a [25]. Finally, SFN led to an upregulated expression of CAV1 [26].

Epigenetic Changes Induced by EGCG

EGCG did not prove to be a powerful epigenetic modulator, limited to increase IL6 expression [28]. Concerning hTERT, EGCG led to an increased binding of repressors such as MAD1 and E2F-1 and to a decreased binding of activators such as c-MYC [27]. 
Gianfredi et al.: SFN and EGCG Restore ER Expression by Modulating Epigenetic Events in the BC Cell Line MDA-MB-231: A Systematic Review and Meta-Analysis

Table 3. List of epigenetic modification induced by dietary bioactive compounds

\begin{tabular}{|c|c|c|c|c|}
\hline $\begin{array}{l}\text { Reference } \\
\text { (first author) }\end{array}$ & Gene & $\begin{array}{l}\text { Epigenetic modification } \\
\text { post treatment }\end{array}$ & Gene expression & Test \\
\hline \multirow[t]{2}{*}{$\begin{array}{l}\text { Lubecka- } \\
\text { Pietruszewska, } \\
2015[24]\end{array}$} & PTEN & $\begin{array}{l}\text { dose-dependent decrease in } \\
\text { methylation by } 22 \% \text { at level of } \\
\text { PTEN promoter }\end{array}$ & $\begin{array}{l}\text { dose-dependent increase by } 72 \% \\
\text { of mRNA PTEN }\end{array}$ & \multirow[t]{2}{*}{$\begin{array}{l}\text { methylation-sensitive } \\
\text { restriction analysis and } \\
\text { quantitative real-time PCR }\end{array}$} \\
\hline & RAR $\beta 2$ & $\begin{array}{l}\text { dose-independent decrease in } \\
\text { methylation by } 25 \% \text { at level of } \\
\text { RAR } \beta 2 \text { promoter }\end{array}$ & $\begin{array}{l}\text { dose-independent increase by } \\
95 \% \text { of mRNA RAR } \beta 2\end{array}$ & \\
\hline $\begin{array}{l}\text { Meeran, } 2010 \\
\text { [25] }\end{array}$ & hTERT & $\begin{array}{l}\text { dose- and time-dependent decrease } \\
\text { in methylation by } 50 \% \text { at level of } \\
\text { hTERT promoter in CTCF region }\end{array}$ & $\begin{array}{l}\text { dose- and time-dependent } \\
\text { downregulation of hTERT } \\
\text { expression }\end{array}$ & $\begin{array}{l}\text { real-time PCR and bisulfite } \\
\text { sequencing analysis }\end{array}$ \\
\hline $\begin{array}{l}\text { Meeran, } 2012 \\
\text { [29] }\end{array}$ & $\begin{array}{l}\text { CpG } \\
\text { islands } \\
\text { of } \mathrm{ER} \alpha\end{array}$ & $\begin{array}{l}\text { increase in acetylation of ac- } \mathrm{H} 3 \text {, } \\
\text { ac- } \mathrm{H} 3 \mathrm{~K} 9 \text {, and ac- } \mathrm{H} 4 ; \text { increase in } \\
\text { methylation by } 54.02 \pm 2.36 \% \text { at } \\
\text { level of promoter sites }\end{array}$ & $\begin{array}{l}\text { reactivation in ER } \alpha \text {-negative } \\
\text { human breast cancer cells }\end{array}$ & $\begin{array}{l}\text { real-time PCR, 5-methyl } \\
\text { cytosine immunostaining } \\
\text { and South-Western dot blot } \\
\text { analysis for 5-methyl } \\
\text { cytosine }\end{array}$ \\
\hline Deb, 2014 [26] & CAV1 & $\begin{array}{l}\text { demethylation at level of CAV1 } \\
\text { promoter }\end{array}$ & $\begin{array}{l}\text { 23.3-fold upregulation of CAV1 } \\
\text { expression }\end{array}$ & $\begin{array}{l}\text { real-time PCR and } \\
\text { methylation-specific PCR }\end{array}$ \\
\hline $\begin{array}{l}\text { Moiseeva, } 2007 \\
{[28]}\end{array}$ & IL6 & - & $\begin{array}{l}\text { three-fold IL6 expression } \\
\text { increase }\end{array}$ & real-time PCR \\
\hline $\begin{array}{l}\text { Meeran, } 2011 \\
{[27]}\end{array}$ & $\begin{array}{l}\text { CpG } \\
\text { islands } \\
\text { of hTERT }\end{array}$ & $\begin{array}{l}\text { dose-dependent decrease in } \\
\text { methylation; time-dependent } \\
\text { decrease in acetylation of ac-H3, } \\
\text { ac-H3K9, and ac-H4 }\end{array}$ & $\begin{array}{l}\text { increased binding of repressor } \\
\text { MAD1; decreased binding of } \\
\text { c-MYC activator; increased } \\
\text { binding of repressor E2F-1 }\end{array}$ & $\begin{array}{l}\text { real-time PCR, bisulfite } \\
\text { sequencing analysis, } \\
\text { and chromatin } \\
\text { immunoprecipitation } \\
\text { analysis }\end{array}$ \\
\hline
\end{tabular}

ac-H3, acetyl H3; ac-H3K9, acetyl H3 at lysine 9; ac-H4, acetyl H4; CAV1, caveolin 1; ER, estrogen receptor.

\section{Discussion}

The results of the present systematic review and meta-analysis show that SFN and EGCG cause induction of ER expression restoration in the MDA-MB-231 cell line, modulating epigenetic events and changes. These bioactive dietary compounds act as modifying specific histone sites and alter the expression of specific genes. Furthermore, they have tissue-specific effects. This further confirms that the induction of these effects may rely on mechanisms and epigenetic pathways specific for breast tissue.

SFN indeed epigenetically modulates PTEN and RAR $\beta 2$, with a RoM of 4.59 (95\% CI 4.055.20), whereas EGCG is a less powerful epigenetic modulator with a RoM of 2.84 (95\% CI 2.60-3.10) in MDA-MB-231 cells. A potential research prospect could be the investigation of the consumption of these compounds.

Dietary bioactive compounds in co-exposure to anticancer drugs may have a synergistic effect [29]. This could demonstrate the importance of a targeted diet during chemotherapy as $\mathrm{BC}$ treatment. The combined effect of dietary bioactive compounds, and some selected anticancer drugs during a course of chemotherapy, may allow lower doses of antiblastics, potentially reducing their adverse events. Furthermore, some dietary bioactive compounds have also been considered as a starting point for the synthesis of new and more powerful anticancer molecules with smaller side effects.

However, even though our study was characterized by some strengths (such as a systematic search and a meta-synthesis), it is plagued by some shortcomings, which include, above all, the high statistical heterogeneity. This was found probably because of the different recruited sample size, the different apoptotic assays (e.g., caspase induction/activity, mitochondrial potential, DNA fragmentation, etc.), different study designs, and different ESs. Another weakness is given by the finding of publication bias, which hinders generalization of the results and calls for caution in their interpretation. 
Nutrigal of
and
Nutrigenetics

\section{Conclusion}

The results of the present systematic review and meta-analysis seem to suggest beneficial effects of dietary bioactive compounds such as SFN and EGCG and their role in BC cells by restoring ER gene expression, modulating epigenetic changes and events, and interfering with tumor growth rate. However, it is also clear that in this type of molecular biology studies, the use of a robust study design is essential to achieve more consistent and reproducible results between the various research groups. On the basis of the above-mentioned limitations, including the evidence of publication bias, further high-quality studies are needed to reproduce and confirm these results.

\section{Acknowledgment}

We acknowledge Miss Deborah Macilletti for linguistic revision of the manuscript.

\section{Disclosure Statement}

The research was conducted in the absence of any commercial or financial relationships that could be construed as a potential conflict of interest.

\section{References}

1 Choudhuri S: From Waddington's epigenetic landscape to small noncoding RNA: some important milestones in the history of epigenetics research. Toxicol Mech Methods 2011;21:252-274.

2 Sharma S, Kelly TK, Jones PA: Epigenetics in cancer. Carcinogenesis 2010;31:27-36.

3 Feinberg AP, Tycko B: The history of cancer epigenetics. Nat Rev Cancer 2004;4:143-153.

4 Filetici P: Epigenetics: a novel tool for early diagnosis and tumor therapy (in Italian). Recenti Prog Med 2015; 106:32-34.

5 Chen H, Landen CN, Li Y, Alvarez RD, Tollefsbol TO: Enhancement of cisplatin-mediated apoptosis in ovarian cancer cells through potentiating G2/M arrest and p21 upregulation by combinatorial epigallocatechin gallate and sulforaphane. J Oncol 2013;2013:872957.

6 Chew YC, Adhikary G, Wilson GM, Xu W, Eckert RL: Sulforaphane induction of p21(Cip1) cyclin-dependent kinase inhibitor expression requires p53 and Sp1 transcription factors and is p53-dependent. J Biol Chem 2012;287:16168-16178.

7 WCRF/AICR: Food, Nutrition, Physical Activity, and the Prevention of Cancer: a Global Perspective. Washington, DC, World Cancer Research Fund/American Institute for Cancer Research, 2007.

8 Caramia G: Childhood feeding, chronic-degenerative disease in adults, and nutrigenomics (in Italian). Pediatr Med Chir 2007;29:309-320.

9 Izzotti A, Cartiglia C, Steele VE, De Flora S: MicroRNAs as targets for dietary and pharmacological inhibitors of mutagenesis and carcinogenesis. Mutat Res 2012;751:287-303.

10 Izzotti A: Molecular medicine and the development of cancer chemopreventive agents. Ann NY Acad Sci 2012; 1259:26-32.

11 DeSantis C, Siegel R, Bandi P, Jemal A: Breast cancer statistics, 2011. CA Cancer J Clin 2011;61:409-418.

12 Joseph PV, Abey SK, Henderson WA: Emerging role of nutri-epigenetics in inflammation and cancer. Oncol Nurs Forum 2016;43:784-788.

13 Hu R, Hebbar V, Kim BR, Chen C, Winnik B, Buckley B, Soteropoulos P, Tolias P, Hart RP, Kong AN: In vivo pharmacokinetics and regulation of gene expression profiles by isothiocyanate sulforaphane in the rat. J Pharmacol Exp Ther 2004;310:263-271.

14 Song X, Zhang M, Chen L, Lin Q: Bioinformatic prediction of possible targets and mechanisms of action of the green tea compound epigallocatechin-3-gallate against breast cancer. Front Mol Biosci 2017;4:43.

15 Tao Z, Shi A, Lu C, Song T, Zhang Z, Zhao J: Breast cancer: epidemiology and etiology. Cell Biochem Biophys 2015;72:333-338.

16 Liberati A, Altman DG, Tetzlaff J, Mulrow C, Gotzsche PC, Ioannidis JP, Clarke M, Devereaux PJ, Kleijnen J, Moher D: The PRISMA statement for reporting systematic reviews and meta-analyses of studies that evaluate healthcare interventions: explanation and elaboration. BMJ 2009;339:b2700. 


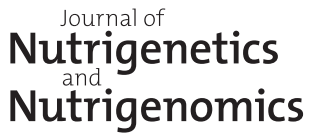

\begin{tabular}{l|l}
\hline J Nutrigenet Nutrigenomics 2017;10:126-135 \\
\hline DOI: 10.1159/000480636 & $\begin{array}{l}\text { (c) 2017 S. Karger AG, Basel } \\
\text { www.karger.com/jnn }\end{array}$ \\
\hline
\end{tabular}

Gianfredi et al.: SFN and EGCG Restore ER Expression by Modulating Epigenetic Events in the BC Cell Line MDA-MB-231: A Systematic Review and Meta-Analysis

17 Chen H, Landen CN, Li Y, Alvarez RD, Tollefsbol TO: Epigallocatechin gallate and sulforaphane combination treatment induce apoptosis in paclitaxel-resistant ovarian cancer cells through hTERT and Bcl-2 down-regulation. Exp Cell Res 2013;319:697-706.

18 Myzak MC, Dashwood WM, Orner GA, Ho E, Dashwood RH: Sulforaphane inhibits histone deacetylase in vivo and suppresses tumorigenesis in Apc-minus mice. FASEB J 2006;20:506-508.

19 Myzak MC, Tong P, Dashwood WM, Dashwood RH, Ho E: Sulforaphane retards the growth of human PC-3 xenografts and inhibits HDAC activity in human subjects. Exp Biol Med (Maywood) 2007;232:227-234.

20 Satya-Prakash KL, Pathak S, Hsu TC, Olive M, Cailleau R: Cytogenetic analysis on eight human breast tumor cell lines: high frequencies of 1q, 11q and HeLa-like marker chromosomes. Cancer Genet Cytogenet 1981;3:61-73.

21 Friedrich JO, Adhikari NK, Beyene J: The ratio of means method as an alternative to mean differences for analyzing continuous outcome variables in meta-analysis: a simulation study. BMC Med Res Methodol 2008; 8:32.

22 Friedrich JO, Adhikari NK, Beyene J: Ratio of means for analyzing continuous outcomes in meta-analysis performed as well as mean difference methods. J Clin Epidemiol 2011;64:556-564.

23 Anzures-Cabrera J, Higgins JP: Graphical displays for meta-analysis: an overview with suggestions for practice. Res Synth Methods 2010;1:66-80.

24 Lubecka-Pietruszewska K, Kaufman-Szymczyk A, Stefanska B, Cebula-Obrzut B, Smolewski P, FabianowskaMajewska K: Sulforaphane alone and in combination with clofarabine epigenetically regulates the expression of DNA methylation-silenced tumour suppressor genes in human breast cancer cells. J Nutrigenet Nutrigenomics 2015;8:91-101.

25 Meeran SM, Patel SN, Tollefsbol TO: Sulforaphane causes epigenetic repression of hTERT expression in human breast cancer cell lines. PLoS One 2010;5:e11457.

26 Deb M, Sengupta D, Kar S, Rath SK, Parbin S, Shilpi A, Roy S, Das G, Patra SK: Elucidation of caveolin 1 both as a tumor suppressor and metastasis promoter in light of epigenetic modulators. Tumour Biol 2014;35:1203112047.

27 Meeran SM, Patel SN, Chan TH, Tollefsbol TO: A novel prodrug of epigallocatechin-3-gallate: differential epigenetic hTERT repression in human breast cancer cells. Cancer Prev Res (Phila) 2011;4:1243-1254.

28 Moiseeva EP, Almeida GM, Jones GD, Manson MM: Extended treatment with physiologic concentrations of dietary phytochemicals results in altered gene expression, reduced growth, and apoptosis of cancer cells. Mol Cancer Ther 2007;6:3071-3079.

29 Meeran SM, Patel SN, Li Y, Shukla S, Tollefsbol TO: Bioactive dietary supplements reactivate ER expression in ER-negative breast cancer cells by active chromatin modifications. PLoS One 2012;7:e37748. 